danken orientierten Vorschlage, in welcher Weise and in welchen Fallen reformbedurftigen Stiftungen aufzuhelfen sei": das gehort ja nicht mehr hierher.

Dagegen kehre ich noch einmal zu dem zurilck, was sich in den Akten zu der Kypckeschen Stiftungsangelegenheit von Kants Hand findet. Es ist, wie schon angedentet, nicht viel. Kant beschränkt sich meist auf ein einfaches Consentio. Einmal beruft er sich auf seine "Krănklichkeit", dic ihn verhindere, an der Lokalinspektion des Mangelsdorffschen Hauses teilzunehmen; einmal tritt er dem Vorschlag Holtzhauers auf Vertagung der Wahl des Inspektors bis nach Vollziehung des Kaufkontraktes ausdrücklich mit den Worten bei: „das Übrige wird sich nachher mit Musse abmachen lassen." Das ist alles und doch nicht alles. Auf einem der beim Senat in Umlauf gesetzten Schriftstücke Holtzhauers findet sich nehen dem "Consentio I. Kant" noch ein kleiner Zusatz von seiner Hand, den er aber selber, offenbar sofort wieder, ausgestrichen und unleserlich gemacht hat. Das Photogramm davon verdanke ich der Güte meines früheren Strassburger Kollegen Herrn Gradenwitz, jetzt in Heidelberg. (Siehe zwischen S. 492/493.)

Ich vermag das Durchstrichene nicht zu entziffern; vielleicht ist ein anderer glücklicher als ich. Oder ist es möglich, durch ein chemisches Verfahren am Aktenstück selber die Worte wieder leserlich zu machen? Es wäre ja nicht uninteressant, selbst auf die Gefahr hin, dass man dabei etwas Menschliches auch am "Weisen" entdeckte, einen kleinen Temperamentsausbruch der Ungeduld" oder des Ärgers vielleicht, den er, kaum dass er ihm Worte geliehen, alsbald wieder zügelt und unterdrückt: die Bemerkung eignete sich dann eben nicht $\mathrm{zu}$ "einer allgemeinen Gesetzgebung"?

So ist die Arbeit von Gradenwitz nicht bloss zierlich, sondern nach mehr als einer Seite hin ein überaus wertvoller Beitrag zur Rechtslehre speziell und darüber hinaus zur Lebensgeschichte, zur Charakteristik und zur Gedankenbildung Kants, ganz abgesehen von den im Schlussabschnitt vorgetragenen beachtenswerten Vorschlägen des juristischen Verfassers zu einer modernen Reform unseres Stiftungswesens, die jeder von uns Angehörigen einer Universität als eine dringend notwendige zu empfinden ja reichlich Gelegenheit hat.

\title{
Ein Druckfehler in Hegels Philosophie des Rechts.
}

Eine der berühmtesten Stellen in Hegels Rechtsphilosophie ist der Zusatz zu $\S 318$ über die öffentliche Meinung und den grossen Mann. Er lautet im 8. Band der vollständigen Ausgabe, der von Eduard Gans besorgt ist, so: „In der öffentlichen Meinung ist alles Falsche und Wahre, aber das Wahre in ihr zu finden ist die Sache des grossen Mannes. Wer, was seine Zeit will und ausspricht, ihr sagt und vollbringt, ist der grosse Mann der Zeit. Er tut, was das Innere und Wesen der Zeit ist, verwirklicht sie, und wer die öffentliche Meinung, wie er sie hier und da hört, nicht zu verachten versteht, wird es nie zu Grossem bringen."

An dem "will und ausspricht" habe ich immer schon. Anstoss genommen. Der grosse Mann soll ja erst finden, in Worte kleiden, den Zeitgenossen künden und dann vollbringen, was die Zeit vernünitiger Weise will und wollen soll, ohne dass sie es noch selber weiss: wie kann sie es also schon selbst aussprechen? Hier steckt offenbar ein Fehler, der aber leicht zu heilen ist. Es muss natürlich heissen: „Wer, was seine Zeit will, ausspricht, ihr sag.t und vollbringt, ist der grosse Mann der Zeit". Das sind die drei Aufgaben des grossen Mannes: auf den Begriff bringen (,ausspricht"), verkündigen (,ihr sagt") und verwirklichen ("vollbringt"), was die Zeit will. So hat Bismarck, was das deutsche Volk wollte, ausgesprochen, ihm gesagt und auch wirklich vollbracht; deshalb war er „der grosse Mann der Zeit".

Theobald Ziegler. 